\title{
Pengembangan Karakter Self Efficacy pada Siswa Berkebutuhan Khusus Melalui Pembelajaran Self Regulated Learning
}

\author{
Fajar Nugraha ${ }^{1}$, Budi Hendrawan ${ }^{2}$ \\ ${ }^{1-2}$ FKIP Universitas Muhammadiyah Tasikmalaya \\ Email: fajarnugraha@umtas.ac.id
}

\begin{abstract}
ABSTRAK
Self efficacy sangat berperan dalam tumbuh kembang seseorang, terutama bagi anak berkebutuhan khusus yang berada pada sekolah inklusi. Rasa percaya diri erat kaitannya dengan pendidikan, pendidikan merupak pilar utama pembentuk karater manusia atas dasar itu maka kemampuan yang dimiliki seorang anak perlu ditingkatkan guna membentuk karakter mereka untuk bisa berbaur dengan teman lainnya. Maka dari itu peneliti ingin mengembangan karakter rasa percaya diri akan potensi yang dimiliki pada anak berkebutuhan khusus yang berada pada sekolah inklusi melalui pembelajaran self regulated learning. Berdasarkan hasil penelitian diketahui bahwa dengan diberikan pola belajar dengan memberikan motovasi-motivasi kepada peserta didik dapat meningkatkan rasa percaya diri mereka. Selain itu yang terutama mereka dapat bergaul dan tidak merasa canggung belajar bersama dengan peserta didik lainnya. Pembelajaran seperti ini perlu ditingkatkan kembali guna meningkatkan rasa percaya diri dan tentunya sebagai upaya pembentukan karakter untuk memperisapkan generasai penerus bangsa di era kemajuan teknologi saat ini. Mempersiapkan generasi muda untuk bisa bersaing perlu persiapan yang matang dan bukan proses yang instan.
\end{abstract}

Kata kunci: karakter; percaya diri, anak berkebutuhan khusus

\begin{abstract}
Self-efficacy plays a crucial role in a person's growth and development, especially for children with special needs who are in inclusive schools. Confidence is closely related to education, education is the central pillar of the formation of human character on that basis, so the abilities of a child need to be improved in order to shape their character to be able to mingle with other friends. Therefore the researcher wants to develop the character of confidence in the potential possessed by children with special needs who are in inclusive schools through self-regulated learning. Based on the results of the study, note that given a learning pattern by giving motivation-motivation to students can increase their confidence. In addition, they especially get along and do not feel awkward learning together with other students. Learning like this needs to be increased again in order to increase self-confidence and of course, as an effort to build character to prepare the next generation of the nation in the current era of technological progress. Preparing young people to be able to compete requires careful preparation and not an instant process.
\end{abstract}

Keywords: character; confidence; children with special needs

\section{PENDAHULUAN}

Self efficacy sangat berhubungan erat dengan keyakinan seseorang bahwa ia dapat mempergunakan kontrol dirinya, motivasi, kognitif, afeksi dan lingkungan sosial. Self efficacy berpengaruh pada perasaan, pikiran, dan tindakan seseorang dalam upaya mencapai tujuan yang diinginkan. Seseorang yang memiliki self efficacy tinggi memiliki potensi untuk mengubah kejadian di sekitarnya dan 
Fajar Nugraha, Budi Hendrawan

Pengembangan Karakter Self Efficacy pada Siswa Berkebutuhan Khusus Melalui Pembelajaran Self Regulated Learning

Early Childhood: Jurnal Pendidikan. Vol. 3 No. 2., November 2019

lebih dekat pada kesuksesan daripada seseorang yang memiliki self efficacy rendah. Oleh karena itu, self efficacy memiliki peran dalam membentuk kreativitas dan ketekunan seseorang dalam mencapai tujuan yang diharapkan, termasuk tujuan penguasaan terhadap keterampilan berbahasa. Seperti pendapat Cervone dan Lawrence (2012: 257) yang mengatakan bahwa individu yang mempunyai self efficacy tinggi menunjukkan upaya dan ketekunan yang lebih besar dibandingkan individu yang memiliki self efficacy rendah. Tidak berbeda halnya bagi siswa yang berkebutuhan khusus.

Di berbagai negara, siswa yang berkebutuhan khusus sekarang menjadi bagian dari sistem pendidikan publik dan memiliki hak memperoleh pendidikan publik yang bebas dan memadai. Siswa yang memiliki bakat khusus dan talenta secara historis telah diikutsertakan dalam perbincangan tentang pendidikan kebutuhan khusus, sementara program-program untuk siswa berbakat tidak seuniversal program bagi siswa yang berkelainan. Dewasa ini, anak-anak yang berkebutuhan khusus meliputi mereka penyandang cacat/keterbelakangan mental (tuna grahita), berkesulitan komunikasi, berkesulitan belajar, penyimpangan perilaku, cacat penglihatan (tunanetra), cacat pendengaran (tuna rungu), cacat fisik dan kesehatan (tuna daksa), berbakat dan kreatif, atau suatu kombinasi dari cacat ganda dan/atau talenta khusus sudah bisa memperoleh pendidikan di sekolah umum yang menyediakan fasilitas inklusi. Namun hal yang menjadi kendala, siswa yang berkebutuhan khusus ini cenderung menarik diri dan tidak bisa bersosialisasi dengan teman dikarenakan keterbatasan yang mereka miliki.

Selain kurikulum dan fasilitas
yang harus ditingkatkan, model siswa berkebutuhan khusus pun harus diperhatikan dengan maksimal. Pembelajaran Self regulated learning diharapkan mampu untuk menjawab pengembangan karakter self efficacy bagi siswa berkebutuhan khusus di SD Inklusi. Pengelolaan diri merupakan salah satu komponen penting dalam teori kognitif social (social cognitive theory). Bandura adalah orang yang pertama kali mempublikasikan teori belajar social pada awal 1960-an. Pada perkembangannya kemudian diganti namanya menjadi teori kognitif sosial pada 1986 dalam buku Social Foundation of Thought and Action: A Social Cognitive Theory. Konsep tentang pengelolaan diri ini menyatakan bahwa individu tidak dapat secara efektif beradaptasi terhadap lingkungannya selama mampu membuat kemampuan kontrol pada proses psikologi dan perilakunya. 
Fajar Nugraha, Budi Hendrawan

Pengembangan Karakter Self Efficacy pada Siswa Berkebutuhan Khusus Melalui Pembelajaran Self Regulated Learning

Early Childhood: Jurnal Pendidikan. Vol. 3 No. 2., November 2019

Menurut Santrock (2008) Self regulated learning atau pembelajaran regulasi diri adalah memunculkan dan memonitor sendiri pikiran, perasaan, dan perilaku untuk mencapai tujuan. Tujuan ini bisa jadi berupa tujuan akademik (Self-Regulated Learning atau pembelajaran regulasi diri adalah memunculkan dan memonitor sendiri pikiran, perasaan, dan perilaku untuk mencapai tujuan. Tujuan ini bisa jadi berupa tujuan akademik), atau tujuan sosioemosional

(mengontrol

kemarahan, belajar akrab dengan teman sebaya) Ormrod (2009) menambahkan self regulated learning adalah pengaturan terhadap proses-proses kognitif sendiri agar belajar sukses. Jadi dapat dikatakan bahwa self regulated learning adalah proses yang membantu siswa dalam mengelola fikiran mereka, perilaku, dan emosi untuk sukses mencapai tujuan belajar mereka. Setelah siswa berkebutuhan khusus ini menerima diri dengan sempurna, siswa mampu untuk beradaptasi dan menempatkan diri di tengah temantemannya. Berdasarkan uraian di atas, penelitian ini mencoba untuk mengembangkan karakter self efficacy bagi siswa berkebutuhan khusus melalui pembelajaran self-regulated learning di SD Inklusi Kota Tasikmalaya.

Bandura (dalam Feist, J. dan Gregory, 2008: 415) mendefinisikan self-efficacy sebagai keyakinan manusia pada kemampuan mereka untuk melatih sejumlah ukuran pengendalian terhadap fungsi diri dan kejadian-kejadian di lingkungannya. Sedangkan Ormrod (2008: 20) mengatakan bahwa selfefficacy adalah penilaian seseorang pada kemampuan yang ada pada dirinya sendiri untuk melakukan perilaku tertentu atau mencapai tujuan tertentu. Berdasarkan definisi para ahli tersebut, dapat disimpulkan bahwa self-efficacy merupakan keyakinan yang dimiliki oleh manusia tentang kemampuannya dalam melakukan suatu tindakan tertentu sehingga mencapai tujuan.

\section{METODE PENELITIAN}

Penelitian ini termasuk jenis penelitian eksperimen-semu (quasiexperimental research), penelitian ini dilakukan dengan memberikan perlakuan tertentu pada siswa eksperimen. Kemungkinan adanya hubungan sebab-akibat dengan menggunakan satu atau kelompok eksperimen (kondisi perlakuan) dan tidak ada kelas pembanding. Metode pengumpulan data yang dilakukan dalam penelitian ini adalah dengan memberikan angket/kuesioner self efficacy, yang kemudian dianalisi dan dijabarkan secara deskripif.

\section{HASIL DAN PEMBAHASAN}

Berdasarkan hasil penelitian terkait pengembangan karakter self efficacy pada siswa berkebutuhan khusus melalui pembelajaran self regulated learning diperoleh gambaran sebgai berikut: 
Fajar Nugraha, Budi Hendrawan

Pengembangan Karakter Self Efficacy pada Siswa Berkebutuhan Khusus Melalui Pembelajaran Self Regulated Learning

Early Childhood: Jurnal Pendidikan. Vol. 3 No. 2., November 2019

\section{Kendala-Kendala yang dalam} Pelaksanaan Pembelajaran Self Regulated Learning

Kendala yang dihadapi dalam penelitian ini yaitu pertama, terkait menarik minat peserta didik untuk bisa aktif dalam proses pembelajaran. Karena peneliti harus mnyesuaikan tingkat kesulitan dalam pembuatan tugas-tugas yang sesuai denga kemampuan peserta didik. Tingkat kesulitan tugas yang diberikan akan mempengaruhi terhadap self efficacy peserta didik (Bandura, 1997). Kedua, selain itu peneliti juga mempertimbangakan keluasan materi yang diberikan kepada peserta didik, agar dapat menyelsaikan tugas ataupun permasalahan yang serupa atau memliki kemiripan dengan apa yang sudah diberikan. Ketiga, adapun kesulitanlainnya yaitu meyakinkan akan kemapuan peserta didik bawhasanya mereka mampu untuk menyesaikan tugas-tugas yang sudah diberikan.

2. Proses Pembelajaran Self Regulated Learning

Pengelolaan diri (SelfRegulated) merupakan salah satu komponen penting dalam teori kognitif social (social cognitive theory). Konsep pengelolaan diri menyatakan bahwa individu tidak dapat secara efektif beradaptasi terhadap lingkungannya selama mampu membuat kemampuan kontrol pada proses psikologi dan perilakunya. Bandura (dalam Filho, 2001) mendefinisikan self-regulated learning sebagai suatu keadaan individu yang belajar sebagai pengendali aktivitas belajarnya sendiri, memonitor motivasi dan tujuan akademik, mengelola sumber daya manusia dan benda, serta menjadi perilaku dalam proses pengambilan keputusan dan pelaksana dalam proses belajar.

Pada tahapan proses pembelajaran dibagi ke dalam empat tahapan di mana guru berperan sebagai model yang kemudian ditiru oleh peserta didik, hingga pada akhinya peserta didik diminta untuk menyimpulkan dan melkasanakan intruksi yang diberikan kemudian bisa mengerjkan tugas/latihan yang diberikan

Tabel 1

Tahapan Instruksi Implementasi Self Regulated Learning Irfan \& Veronika. (2014)

\begin{tabular}{|l|l|l|}
\hline Tahapan & $\begin{array}{l}\text { Performa } \\
\text { Tugas }\end{array}$ & Intruksi Tugas \\
\hline $\begin{array}{l}\text { Tahap 1: } \\
\text { Cognitiv } \\
\text { e } \\
\text { modelin } \\
\text { g }\end{array}$ & $\begin{array}{l}\text { Guru } \\
\text { menunjukk } \\
\text { an perilaku } \\
\text { yang } \\
\text { diinginkan. }\end{array}$ & $\begin{array}{l}\text { Guru } \\
\text { memberikan } \\
\text { instruksi } \\
\text { dengan kata- } \\
\text { kata dan } \\
\text { contoh } \\
\text { konkrit }\end{array}$ \\
\hline $\begin{array}{l}\text { Tahap 2: } \\
\text { Overt, }\end{array}$ & $\begin{array}{l}\text { Peserta } \\
\text { didik }\end{array}$ & $\begin{array}{l}\text { Guru } \\
\text { memberikan }\end{array}$ \\
\hline
\end{tabular}


Fajar Nugraha, Budi Hendrawan

Pengembangan Karakter Self Efficacy pada Siswa Berkebutuhan Khusus Melalui Pembelajaran Self Regulated Learning

Early Childhood: Jurnal Pendidikan. Vol. 3 No. 2., November 2019

\begin{tabular}{|l|l|l|}
\hline $\begin{array}{l}\text { External } \\
\text { euidanc }\end{array}$ & $\begin{array}{l}\text { menampilk } \\
\text { an perilaku } \\
\text { yang } \\
\text { diinginkan }\end{array}$ & $\begin{array}{l}\text { instruksi } \\
\text { dengan kata- } \\
\text { kata dan } \\
\text { contoh } \\
\text { konkrit }\end{array}$ \\
\hline $\begin{array}{l}\text { Tahap 3: } \\
\text { Overt, } \\
\text { Self } \\
\text { Guidanc } \\
\text { e }\end{array}$ & $\begin{array}{l}\text { Peserta } \\
\text { didik } \\
\text { menampilk } \\
\text { an perilaku } \\
\text { yang } \\
\text { diinginkan }\end{array}$ & $\begin{array}{l}\text { Peserta didik } \\
\text { mengulangi } \\
\text { instruksi }\end{array}$ \\
\hline $\begin{array}{l}\text { Tahap 4: } \\
\text { Faded, } \\
\text { Overt } \\
\text { self }\end{array}$ & $\begin{array}{l}\text { Peserta } \\
\text { didik } \\
\text { menampilk } \\
\text { an perilaku } \\
\text { e }\end{array}$ & $\begin{array}{l}\text { Peserta didik } \\
\text { membisikkan } \\
\text { instruksi }\end{array}$ \\
\hline $\begin{array}{l}\text { Tahap 5: } \\
\text { Covert } \\
\text { self } \\
\text { instructi } \\
\text { diinginkan }\end{array}$ & $\begin{array}{l}\text { Peserta } \\
\text { didik } \\
\text { menampilk } \\
\text { an perilaku } \\
\text { yang } \\
\text { diinginkan }\end{array}$ & $\begin{array}{l}\text { Peserta didik } \\
\text { berpikir } \\
\text { dengan } \\
\text { tenang } \\
\text { mengenai } \\
\text { instruksi dan } \\
\text { melaksanakan } \\
\text { nya }\end{array}$ \\
\hline
\end{tabular}

\section{Pengembangan Self Efficacy} melalui Pembelajaran Self Regulated Learning

Dari hasil proses pembelajaran self regulated learning dapat di diketahui bahwa ada perubahan karakter yang dialami oleh peserta didik. Mereka menjadi memiliki rasa percaya diri untuk bisa menyelesaikan tugas-tugas yang diberikan. Untuk memperoleh rasa percaya diri tersebut tidak bisa langsung dirasakan tapi memerlukan tahapan-tahapan sebagaimana menurut Schunk (1999) pengelolaan diri atau self-regulation merupakan proses yang berputar. Gambaran proses berputar ini dilukiskan oleh Zimmerman dengan tiga tahap model pengelolaan. Pertama, forethought phase (pemikiran sebelumnya), yaitu performasi actual yang mendahului dan berkenaan dengan proses pengumpulan langka untuk suatu tindakan. Kedua, performance (volitional) control phase, yaitu mencakup proses yang terjadi sebelum belajar yang memengaruhi perhatian dan perilaku. Ketiga, selama terjadi setelah performansi individu merespons pada usahanya.

\section{SIMPULAN}

Pendidikan berhak diterima oleh siapa saja, bahkan untuk anak berkebutuhan khusus. Karena pada dasarnya mereka memiliki kemampuan yang terkadang belum kita gali. Dengan pembelajaran self regulated lerning ini sendiri dapat terlihat bahwa self efficacy siswa berkebutuhan khusus ini mengalami perkembangan. Mereka menjadi sedikit lebih memiliki rasa percaya diri dan percaya akan potensi yang ada dalam diri mereka untuk bisa meyelesaikan permasalahan yang dihadapi. 
Fajar Nugraha, Budi Hendrawan

Pengembangan Karakter Self Efficacy pada Siswa Berkebutuhan Khusus Melalui Pembelajaran Self Regulated Learning

Early Childhood: Jurnal Pendidikan. Vol. 3 No. 2., November 2019

\section{UCAPAN TERIMAKASIH}

Dalam menyelesaikan penelitian ini, banyak pihak yang telah membantu sehingga tak lupa kami ucapkan terima kasih kepada semua terutama kepada Kementerian Riset, Teknologi, dan Pendidikan Tinggi Republik Indonesia.

\section{DAFTAR PUSTAKA}

Bandura, A. (1997). Self Efficacy The Exercise of Control. New York: W.H Freeman and Company

Cervone, D. \& Lawrence A. P. (2012). Kepribadian: Teori dan Penelitian. Penerjemah: Aliya Tusyani, dkk. Jakarta: Salemba Humanika.

Feist, J. \& Gregory J. F. (2008), heories of personality Edisi Keenam. Penerjemah: Yudi Santoso. Yogyakarta: Pustaka Pelajar.

Irfan, M \& Suprapti, Veronika. (2014). Hubungan Self-Efficacy Dengan Penyesuaian Diri Terhadap Perguruan Tinggi Pada Mahasiswa Baru Fakultas Psikologi Universitas Airlangga. Jurnal Psikologi Pendidikan dan Perkembangan: Volume 3, No. 3

Ormrod, J. E. (2008). Psikologi Pendidikan Jilid 1. Jakarta: Penerbit Erlangga

Ormrod, J. E. (2009). Educational Psyhology Developing Learning Jilid 2. Ahli Bahasa Amitya Kumara. Jakarta: Penerbit Erlangga.
Santrock, J. W. (2008). Psikologi Pendidikan. Edisi pertama Diterjemahkan oleh Tri Wibowo B.S. Jakarta: Kencana

Schunk, D.H. \& Ertmer, P.A. (1999). Self-regulatory process during computer skill aquisition: Goal and self-evaluative influences. Journal of Educational Psychology, 91, 251-260. 